\title{
Parenthood and Partnerhood in the Context of Involuntary Childlessness and Assisted Reproduction in Greece
}

\author{
by Aglaia Chatjouli, Ivi Daskalaki and Venetia Kantsa \\ University of the Aegean; Panteion University of Social and Political Sciences; University of the \\ Aegean
}

Sociological Research Online, 22 (2), 3

$<\mathrm{http}: / /$ www.socresonline.org.uk/22/2/3.html>

DOI: $10.5153 /$ sro.4207

Received: 16 Sep 2016 | Accepted: 6 Feb 2017 I Published: 31 May 2017

\begin{abstract}
Ta en oiko mi en dimo is a popular Greek proverb meaning that whatever happens at household [ oikos] should not be exposed into public [ dimos]. In the Greek cultural context sexuality, reproduction, family relations belong to the realm of private domesticity. In this paper we trace the way women and men in Greece resituate themselves towards their reproductive desires and decisions, towards medicalized reproduction and towards each other, when in the context of involuntary childlessness, infertility and ART use, reproduction moves outside the body and the private sphere of the household and becomes part of the public sphere exemplified in state laws, doctor's decisions, hospital laboratories, IVF forums.

Drawing from the research project (In)FERCIT and based on 130 semi-structured interviews of both women and men the paper explores the shifts related to parenting, the imagining and making of a family, the couple, in the context of neoliberal reproductive potentialities. Which relationships and practices change through the ongoing challenges of infertility and the experience of ART? What is kept within the couple and what is shared with others (family members, friends, strangers, experts)? What is the significance of reproductive socialities in managing the demands of infertility within an ever-increasing intensification of parenthood? How does this challenging context reinforces or weakens the couple's relationship, their reproductive agency and desire? Finally we explore how proper parenthood but also proper partnerhood are constructed in Greece following local demands regarding family making and localized medicalization of reproduction.
\end{abstract}

Keywords: Assisted Reproduction Technologies, Infertility, Parenthood, Motherhood, Couple, Family-Making

\section{Research Themes and Methodology}

1.1 In the introductory chapter of his book The Reinvention of Primitive Society Transformations of a Myth an anthropological study of kinship, Adam Kuper (2005) argues that specific ideas and topics in anthropology have the tendency to reappear through the years disguised in different theories and maintains that transformations allow the same topics to circulate. Research on parenthood and especially motherhood, a resilient topic of interest for the first and second generation of Greek ethnographers, re-emerged at the beginning of the $21^{\text {st }}$ century. Both are re-examined beyond the 'domestic model of gender' and in a broad used as central concepts for the investigation of topics such as ethnicity, the state, the law, demography, medical practices and new reproduction technologies. The paper follows this body of work in Greece as well as anthropological literature on reproduction, parenthood and family drawing from the research project (In)FERCIT -(In)Fertile Citizens: On the Concepts, Practices, Politics and Technologies of Assisted Reproduction in Greece. An Interdisciplinary and Comparative Approach, a three-year research program (September 2012 - September 2015).[1] 
documentation, the (In)FERCIT project produced a detailed, multi-sited ethnographic account of assisted reproduction concepts, practices, politics and technologies in Greece; it also related them to legal issues and human rights on (in)fertility and reproduction, and provided a comparative perspective that associated the Greek case with research findings conducted in selected European and non-European countries. In the present paper we draw from 130 semi-structured interviews with both women and men, who have sought medically assisted fertility treatments, in order to explore the ways infertility and assisted reproduction can be either bound to the household or more open, as well as the shifts triggered in relation to reproduction, parenting, the imagining and making of a family. The interviews were conducted using the snow-ball technique from May 2013 to June 2014 in Athens and the Greek periphery (Thessaloniki, Larisa, Lesvos. Korinth, etc).[2]

Based on the aforementioned ethnographic material, this paper focuses on parenthood and partnerhood in the context of involuntary challenges, infertility and ART use. The paper aims to unravel the challenges inflicted upon the couple and the impact on the relationship, the reproductive agency, and the desire and decision making; the patterns of disclosure (within the couple, between family members, friends, strangers, experts); the formation of other significant socialities; how the neoliberal context of 'reproductive potentialities' [3] mediates imagined and practiced parenthood and partnerhood. By elaborating on the meanings attributed to the couple, we argue that what is at stake beyond overcoming involuntary childnessness is maintaining the integrity of the relationship in order to contain the 'intensification of parenting' (see also Lee et al.2014). We trace the desire to become a parent vis à vis the dominant and emerging gendered parental and conjugal normativities, the way medicalization, regulation and in many ways subsequent normalization of involuntary childlessness, infertility and ART use mediate the construction of not only parenthood but also partnerhood. Understanding the particularities of the desires and the decisions linked to becoming a mother, a father, to having a child in the house, in terms of the prerequisites presented -often linked to age, gender asymmetries, life accomplishments- it can illuminate the way existing parenting cultures in Greece are fertile ground for the incoming reproductive technologies as well as the way these technologies are 'localized' (Inhorn and Birenbaum-Carmeli 2008); it can also reconceptualize dominant ideas about the project of family making. ${ }^{[4]}$

1.4 We argue that ultimately the challenge of infertility informs the autonomy and integrity of the couple with regard to the wider family, the individuality of reproduction and self-regulation within the wider context of neoliberal reproductive potentialities. Particularly in the case of Greece, the technologies are widely offered, mostly by the private sector where the state doesn't exercise any coordinated control. Such local circumstances add to the stress and anxiety of reproductive decision-making inflicted on each parent as an individual and as a couple. The ambiguity faced by the couple when they have to choose technologies, clinics and doctors, and to test and decide for themselves, is coupled with the empowering experiences of managing and often overcoming involuntary childlessness in a cultural context whereby family making (still) acquires high symbolic value (Chatjouli et al. 2015).

\section{The Cultural, Medical and Legal Context of Art in Greece}

2.1 Greece has been described as a society where kinship and family relations play a crucial role in the definition of female and male identities, while full adult status for both women and men is obtained through marriage and having children [apoktisi paidion] (Loizos \& Papataxiarchis 1991). Parenthood and especially motherhood has persistently provided a metaphor for the nation's continuity and integrity appropriated by both the state and the church who have been steadily arguing for the necessity of reproduction particularly as a response to the 'demographic problem' (i.e. low birth rates) primarily attributing the burden of this necessity to women (Paxson 2003, 2004; Halkias 1998; Athanasiou 2006; Kantsa 2006, 2013b; Papataxiarchis 2014). Despite the rise of alternative family forms, of same sex households, of single men and women choosing not to have children (see Kantsa 2014a), the 'dominant biopolitical regime' in Greece remains 'procreation within marriage' (Papataxiarchis 2013: 238). [5] Additionally, ethnographers looking into Greece have demonstrated the prominent role of religious idioms as metaphors for gender and kin relations and practices, and have particularly elaborated on the powerful idiom of Panayia (All Holy Mary), ${ }^{[6]}$ which ascribes a significant value to motherhood and associates proper motherhood with offering, suffering and sacrifice (Paxson 2004, 2006).[7]

2.2 According to the more recent ethnographically documented shifts in representations of 'good motherhood', a 'good' mother is also a responsible mother, someone who takes care of her own personal wellbeing and respects her personal desires (Vlachoutsikou 2013), who has consciously decided and planned to become a mother, a mother who raises sosta paidia (good children), or raises children sosta (properly) (Paxson 2004: 55), or 'in the right way' (Kantsa 2006: 363), as well as a mother who is also a good citizen Paxson 2004: 211). In this sense, women's preoccupation with becoming 'good' or 'proper' mothers indicates that the decision to have a child is not merely premised on the desire for a child and becoming a parent but on a great deal of 
rational thinking around particular skills and pre-conditions for fulfilling 'good' or 'proper' parenting. It also points to a shifting towards a more individualistic notion of the self, of proper motherhood and womanhood based on everyday life choices relevant to the process of the making of the self, resulting from a wide pool of availabilities, lifestyles and potentialities, often global in nature, variously localized, echoing neoliberal subjectivities whereby self-regulation, individual risk taking and decision making have become central existential directives.

2.3 When it comes to reproductive management, the existing ethnographic accounts would agree that the intense medicalization of reproduction in Greece has acted as a means for preparing the ground for the extended use of ART. Medicalized reproduction has been a target of ethnographic research in Greece more than thirty years now focusing initially on issues related to pregnancy and birth (Georges 2008; Traka 2013). Georges (2008) describes how Greek doctors, women and their families have appropriated the use of ultrasound. She documents the wide and quick spread of this technology and how it became the norm constituting an integral and almost inseparable part of the experience of pregnancy and fetal development. Ultrasounds became the baby's first pictures already presenting a different cultural framing of reproduction when only until recently pregnancy was predominately announced only after it became visible. The normalization of such technologies involves the technologization of pregnancy and mediates the shift of care provision from certified or non-certified midwives (women) to expert doctors, gynaecologists and technicians (men mostly), as well as the shift of care provision locations from the home to the clinic/hospital. The same applies to the case of birth technologies. Home birth and natural birth have been substituted by hospital birth and caesarean deliveries. The high number of caesarean sections -one of the highest worldwide (Georges 2013)- exemplifies the intense medicalization of reproduction in this specific cultural context. Technologies used for the termination of pregnancies and for the control of reproduction have also become normalized in Greece (Halkias 2004); in addition, the advent of genetic screening technologies have brought about the biomedical monitoring of reproduction even before conception and all the way until birth, as in the case of prevalent inherited conditions like thalassaemia (Chatjouli 2012), while testing for genetic conditions throughout pregnancy (amniocentesis, CVS) has become a regular choice.

2.4 The dominance of reproductive technologies has been also studied in Greece both in terms of the 'authority of knowledge', looking into, for instance, the relationship between midwives and gynaecologists, and also in relation to the engagement of pregnant women themselves (Traka 2013). To this respect, medicalization is problematized also in relation to biopower and biopolitics (Foucault 1997, 1998). Ethnographic accounts of the extensive biomedicalization of reproduction in Greece have demonstrated that reproductive technologies are greatly used as widely available reproductive choices by responsible future mothers, who have appropriated the medical rational underlying a healthy pregnancy. In other words, normalization of technological use as a biopolitical mechanism and 'disciplinary power' (Foucault 1990) underlying the practice of power, according to the Foucaudian analytics, is evident in the case of perinatal medical care. A pregnancy without an ultrasound, for instance, is no longer considered 'normal'. Indeed, women who refuse, or most appropriately don't choose such technologies might be considered irresponsible especially towards the wellbeing and the rights of the embryo. Ultimately, such progressive, modernized, global, controlling and surveilling technologies are chosen by the users 'for their own wellbeing', typical of biopolitical subjectivities. Only recently the highly medicalized institution of perinatal care has been challenged by a small fraction of women and medical stuff, especially regarding natural births (Chronaki 2015).

2.5 The highly medicalized context of reproduction in Greece in tandem with the cultural value attributed to parenthood mentioned above have provided a fertile ground for the establishment of an ART reproductive 'industry', particularly in the private sector, within a highly 'permissive' legal framework. Greece has one of the highest ratios between assisted reproduction clinics and medical centres, and its population, as well as one of the most 'liberal' legal settings among European countries, coupled with the absence of state control. All this points to a characteristic neoliberal context within which individuals take responsibility, risks and decisions. IVF was introduced in Greece in 1984 and legal regulation came eighteen years later mainly consisting of three Laws (Law 3089/2002, Law 3305/2005 and Law 69 (I)/2015).[8] The Greek legal context allows for preimplantation genetic diagnosis, embryo freezing, anonymous sperm donation, anonymous egg donation, embryo donation, surrogacy, research on genetic material (donated gametes and fertilized eggs) and the free transportation of genetic material and fertilized eggs from and to other European countries.

2.6 Despite the highly medicalized context of reproduction in Greece, the cultural significance of parenthood and the 'permisive' legal framework, the voice of the infertile patient and the ART consumer is not officially and formally acknowledged. Even though the state is publicly concerned with the low birth rates in the country (Halkias 1998, 2004; Athanasiou 2006, 2014; Paxson 2002, 2004) the needs and trajectories of the infertile citizens are somewhat underestimated, underrepresented and silenced, something that may be well understood 
in a context of neoliberal reproductive potentialities, whereby the individual -user of the technologies- is valued in consumer-market terms. The making of a family in Greece is overall under-supported in terms of institutions helping new families. This, as such, is a contradiction that has implications in the management of involuntary childlessness, infertility and ART use. Despite the cultural necessity to make a family, the struggle to do so is an individual endeavor.

2.7 Even though there are multiple socio-cultural facets to the use of ART in Greece - conceptualizations of parenthood, meanings of 'infertility', the permissiveness of the Greek laws, the absence of state control, the high number of medical centres and clinics, the stance of the Orthodox church- the majority of relevant research is about its legal dimensions from a legal perspective (Kotzabassi 2003, 2015; Kounoyeri-Manoledakis 2005, 2015; Kriari-Catranis 2003; Fountedaki 2007; Trokanas 2011; Milapidou 2011; Papadopoulou 2015) with a few publications on its psychological aspects (Abatzoglou et al. 2006; Papaligoura 1992, 2013). Ethnographic accounts are still relatively few (Paxson 2003, 2006; Kantsa 2006, 2011, 2013a, c; Toundasaki 2013, 2015). To that respect and regarding research on parenting cultures, the pioneering work of Heather Paxson (2003, 2004, 2006) discussed a socially and historically constructed shift taking place in the last decades in Greek women's views on procreation from an ethic of service towards an ethic of choice, echoing also the dynamics of neoliberal reproductive potentialities. Women who undertook IVF during the 1990s in Athens consider the use of medical assistance in reproduction as 'spiritual kin work' and as a means to accomplish their womanly status by normalizing it in reference to ideologies of motherhood in which womanhood is achieved through suffering and sacrifice, highlighting therefore the localization of these global potentialities at that point in time.

2.8 ART use is perceived as leading both to a sense of losing control of one's reproductive life in the face of the myriad of dilemmas, choices, physical, medicalized, gendered and sexualized hardships and technologized reproduction, and to a sense of regaining control of one's (uncertain) reproductive potential, via the re-birth of hope and of 'other ways' to have a child (Chatjouli et al 2015) This double and seemingly contradictory sense has been documented in relation to the context-specific (localized) appropriation of medical technologies whereby medical authority is at the same time informed by and informs local power relations and dominant institutions and most often gendered asymmetries (Lock \& Kaufert 1998; Inhorn 1994; Rapp 1999). The same applies to the Greek setting as it has been thoroughly studied together with other reproductive technologies beyond ART mentioned above (ultrasound, abortion, contraception, childbirth, caesarean section, family planning) in juxtaposition to local gendered relations and norms permeating sexuality, marriage, family and kinship (Lefkarites 1992; Georges 2008, 2013; Halkias 1998, 2004; Athanasiou 2006, 2014) and regarding ART (Paxson 2003, 2004, 2006; Kantsa 2011, 2013c, 2014b). The way Greeks have widely accepted medical technologies, giving rise to the making of medical subjectivities, but also been selectively and growingly critical about them, has been explained, on the one hand, through the desire to become modern after World War II, and how this drive has taken particular shapes based on local biologies and local realities of the gendered and relational personhood; and on the other, through the rise, on a global scale of the sceptical and informed patient-client who is confronted with not only the benefits but also the risks of biomedicine. Biomedical innovation brings therefore potentiality, along with risk and responsibility, self-surveillance and choice. The expectations of the couples turning to reproductive biomedicine for help are filtered both by hope and doubt and so are their experiences -positive, negative, celebratory, critical- throughout their journey of achieving parenthood. Many researches have highlighted that this new technological potentiality doesn't come without costs, risks, ambiguity and a sense of insecurity and uncertainty (Franklin 1997; Inhorn \& van Balen 2002). As in the case for many other facets of biopolitical subjectivity in late modernity, (in)fertile citizens are faced with burdens of decision-making, responsibilities, taking risks in terrains of high expertise and as a result of a greater control over their bodies, lives, present and future (Rabinow 1996; Rapp 1987, 1991, 1999; Novas 2006; Rose 2007; Chatjouli 2012, 2014a, 2014b; Kantsa 2014a, 2014b). In the Greek reality of ART where the techniques offered are plenty, the confusion brought by the many options and professional opinions often causes anxiety to the users and a sense of mistrust towards the experts' community together with the discourse of trust and hope (Kantsa 2014b).

\section{Aspiring Parenthood and Partnerhood}

3.1 Ta en oiko mi en dimois a popular Greek proverb meaning that whatever happens at a household [oikos] should not be made public [dimos]. It underlines that in the Greek cultural context sexuality, reproduction, family relations belong to the realm of private domesticity. But what happens to aspiring parenthood and partnerhood in the context of infertility when reproduction moves outside the body [ekso-somatiki] ${ }^{[9]}$ and outside the private sphere of the household and becomes part of the public sphere exemplified in state laws, doctor's decisions, clinical laboratories, IVF forums? As the household boundaries are becoming more flexible, other actors (experts, clinical staff, co-sufferers), new norms and practices enter the scene mediating the imagining and 
practising of both parenthood and partnerhood.

\section{Desires and Decisions}

The primary focus of our study was on our interlocutors' desire to have a child and become parents.

Different individual and family stories, expectations and projections, encounters with age, time and 'nature', inform gender-specific attitudes and feelings. Although both women and men may in a few cases interpret their desire to have a child principally as a naturalized need to procreate, for women that desire often is not only perceived as a call by 'nature' for procreation but also as a gender-specific individualized need that is premised on undisputable biological features and processes based on the function of the female reproductive system. This instinctual drive or existential need may have always-been-felt or emerged either progressively or abruptly at a certain point in time, as frequently female interlocutors put it, "when the biological clock starts ticking" or when, in forty-one-year-old Valentina Chiotis' words, "the biological clock awakens". By contrast, men who acknowledge their desire to have a child and become fathers as an ostensibly always-existing emotion, then this emotion tends to involve a process of naturalization of cultural ideals about parenthood, reproduction and the family, ideas that are transmitted within the family and other social institutions. This is mirrored in the words of forty-three-year-old, Stelios Eleftheriou, who got a child through natural conception after failed attempts to conceive through sperm injections and IVF:

\section{[...] yes, I've always wanted to have a family, ...indeed, I think that this is the purpose in life...and I've always thought that if I hadn't had a family, from a certain point in time onwards my life would have been very boring, especially if you live in a society which has trained you to do so [...].}

3.3 Despite the apparent categorization of the interlocutors' understandings of the desire to have a child into those who have 'always-had-that-desire' and those whose urge surfaced at 'a-certain-point-in-life', the wish to become a parent, in almost all cases, is also understood in relation to time as a complex interweaving of two important factors: 'social maturity' and 'biological maturity'. This is actually what a female interlocutor, forty-fiveyear-old Viki Pappa, who got two children through IVF and one through natural conception described as "social age" and "biological age". Moreover, the interlocutors have elaborated a discourse surrounding women's and men's new tendency to postpone reproduction to a later stage in life for the sake of fulfilling their individual aspirations and joint -in cases of couples- projects. Although this tendency pertains to both women and men, it is acknowledged by women and men alike that women's decision to postpone pregnancy to a later stage in life causes more complications than that of men. This is because the postponement of pregnancy by women is directly associated with biological age and the function of the female reproductive system that inevitably leads to menopause.

3.4 Some women and men admitted that their aspirations about having a child have been premised on culturally constructed perceptions of reproduction, parenting and family, which are all intrinsically associated with particular modes of fulfilling age and gender specific roles in the context of marriage and the conjugal household where both members of the family and members of wider social circles belong, such as friends and acquaintances. For other interlocutors, though, the primary role of 'culture' in shaping their desire for having a child and becoming parents has been understood less as a cultural ideal anchored to 'tradition' and more as a cultural ideal anchored to modernization processes of Greek society, predominantly being processes of individualization. For instance, thirty-nine-year-old, Mimi Lioliou, who had sought to have a child during her late thirties through a failed cycle of sperm injection and a failed IVF, claimed about her generation: "We had to live our life, study, find the perfect man, because there was also a certain standard of living". A similar view also came from fifty-year-old, Menia Stamatouli, who eventually adopted a child after many failed cycles of sperm injections and fourteen IVF cycles. Menia explained that although she had been pregnant with her future husband and had an abortion, their decision to have a child came only when they had both completed their studies and had successful professional careers.

\footnotetext{
When I was eighteen, when I was in my first year of studies. I thought it was impossible to keep a child. It was exactly when we had started studying. I couldn't believe it, I had always been careful. [...] Since then we got married we came back from France where N. was doing his Masters and I found a job here -anyway I was in Paris for a Masters as well. [...] I think that we placed more emphasis on the career, to make our lives better, to have a good job, to be independent.
}

3.5 No matter what the 'origins' of the desire for a child are, the child is aspired as 'bonding' the couple and the family, 'completing' the nuclear household and 'filling a house with joy', since reproduction constitutes the fundamental element of the family. Most interlocutors acknowledged that, on the one hand, the child stands for an imagined, aspired or actual experience of being related to a child, as well as to a new family member who 'fills' 
the household and makes the family complete in quotidian life and everyday practices in the context of interdependent family relations. On the other hand, it represents the 'offspring' of the parents, the couple and the family, 'their 'legacy' and 'projection', as well as the 'bond' that connects generations, ensuring the 'continuity' of kin relatedness through time and space. These representations of the child seem to be deeply rooted in religious idioms and ideologies which associate the conception and birth of a child with God's Will and 'teknopoiía, the making of children, as a matter of divine service' (Paxson 2004: 43), additionally, in depictions of the continuity of the couple as becoming 'one flesh in body of the child' (Paxson 2004: 43).

However, when it comes to the decision to have a child this is not merely premised on the desire for a child and becoming a parent, but on a great deal of rational thinking around the prospective parents' parenting skills and pre-conditions for fulfilling 'good' or 'proper' parenting. This rational thinking transforms the desire and yearning for having a child to a well-thought-out decision made by women and men alike, also characteristic during the process of managing infertility and ART use. A 'good' or 'proper' parent is primarily seen by most as the woman or the man who, no matter how much she/he desires a baby,[10] she/he bases the actual decision of having a child on the precondition that what comes first is the well-being and needs of the child rather than the well-being and needs of the parents. Indeed, what most interlocutors highlighted is that parenthood should by no means be the outcome of random choices or a mere response to 'nature's call' or the prospective parents' desire for having a child. Instead, it should be the outcome of a 'mature decision' of women and men who consciously and, in cases of couples, jointly, decide to devote themselves to bringing up the child on the values of prioritizing the child's well-being and needs. Forty-one-year-old Sofia Tobazi comments:

Oh I can't stand hearing 'our child just happened and we kept it' ... This is not a lottery! [...] It should be a choice, I want to be a parent and I'm trying to make it.

3.7 In addition, the 'good' or 'proper' parent is seen as the woman or man who not only has carefully thought about what it actually takes to become a parent, committing herself/himself to undertaking the 'burden' of parenting responsibilities, but also someone who takes into serious consideration her/ his and the partner's or the supportive environment's potentiality for bringing up a 'happy child' and a 'useful member of the society'.

3.8 Even though material conditions, such as the existence of a 'proper' household as a suitable environment for bringing up a child or the means which will contribute to the child's 'proper' development in terms of nurture, care, health, safety and education, play an important role in the interlocutors' conceptualizations of the 'good' or 'proper' parent, what is more important is the parents' degree of intended commitment in the socioemotional development. This involves a commitment to a continuous 'offering' of genuine emotions, such as love, affection, devotion, moral guidance and support towards the child. Yet it also involves the parents' total commitment to 'create' fulfilled, happy, strong, responsible and balanced human beings through which the children will eventually become good persons [kaloi anthropoi]. Nana Nikolaou (a thirty-three-year-old woman, pregnant to twins through IVF after two failed sperm injections) described the upbringing of a child as a process of transforming a human being (a child) into an individual and member of the society through plasimo (giving shape to play dough), something that involves the transmission of emotions, aspirations, values, knowledge from parents to children: 'It means that you create a human being, you make a human being, [...] you give it shape like play-dough $[\ldots]^{\prime}$.

3.9 This task is seen as hard work that demands both social maturity (usually attained through biological maturity) and the physical capacity that often declines with biological ageing. A distinction is also apparent between kano paidi (having a child) that connotes with the biological process of childbearing versus megalono paidi (bringing up a child) that highlights the importance of the qualities and attributes involved in 'good' or 'proper' parenting which makes 'good children' and, in return, 'happy parents'. Labris Christou, a man who got a child through his first IVF attempt, bringing up a child primarily meant to him that the prospective parent(s) should have the qualities of a 'good person':

I want to bring up a human being, I think, you can call me anything you like, but I think I'm - above the average- a good person and Valentina is a good person, indeed we can bring up a human being in a good way and to make this person, to enjoy looking at this person and say we actually did something.

3.10 The commitment and conscious decision making of future parents is also characteristic and in a way accentuated when couples are faced with reproductive difficulties. We found that strong commitment to the project of family making is further highlighted in terms of commitment towards one's partner and towards the integrity of the couple in many ways challenged via involuntary childlessness and reproductive failures. 
3.11 No matter what the 'origin' of women's and men's desire for having a child is ('always-existing' or 'generated-at-acertain-point-in-time'), for most of them it turns into a well-thought-out decision to start trying for a child only when the precondition of a 'quality' or 'mature' relationship is fulfilled. A 'quality' or 'mature' relationship is not only seen as an intimate relationship between a woman and man premised on sincere emotions of love, sexual attraction, care, mutual affection, devotion, and trust, but also as the acknowledged by the partners prospect of following 'a common route' in life primarily through sharing the intimate spaces of a nuclear household which may provide the basis for the making of a new family, in most cases via marriage. A 'quality' or 'mature' relationship is also seen as a relationship in which both partners happen to share similar values about 'how children should be brought up' and 'what a family stands for'. Whilst conjugality is not necessarily a precondition for the making of a new family, at least at its initial stages, the appropriate relationship seems to be based on the fundamental principles of 'complementarity, mutual dependency, and ideal equality', which Loizos \& Papataxiarchis (1991b: 7) underline as a prerequisite for the conjugal mode.

3.12 More individualistic imaginaries of motherhood, mentioned above, together with the importance given to rational decision making when it comes to becoming partners-as-prospective parents, become part of the cultural repertoire activated when the couple faces infertility and the difficulties of overcoming reproductive failure along with the emphasis given in the achievement of a loving and supporting familial environment which starts from the couple's quality relationship vis à vis personal histories, dominant cultural norms of achieving adult status as a woman and as a man, expectations stemming from the wider kin environment.

\section{Mediated Parenthood - Constructing 'Proper' Partnerhood}

4.1 In the case of repetitive failed attempts to get and remain pregnant the scene changes. New persons, techniques, decisions and choices mark their entrance. During the initial period of involuntary childlessness the couple is primarily preoccupied by their own failing reproductive bodies and failed attempts and the whole experience remains mostly the couples' own, private, intimate matter. Gradually while searching for a reason and a solution, along with the familiarization of a difficult reproductive trajectory comes the externalization of this problem, the distancing of the reproductive desire from the sexual act and the gradual denaturalization of 'natural attempts' (Chatjouli et al 2015: 85-91). What is introduced in the conjugal space and the relationship between partners, is the knowledge of other possible ways and reproductive potentialities, of other people (experts and non-experts) that know something more, that can offer guidance, that ultimately and variously mediate (disrupt, transform, heal) the reproductive process and conjugal dynamics.

4.2 The difficulty to have children becomes medicalized and pathologized along with the transformation of both women and men -potential future parents- into infertile patients-consumers and clients, leading, on the one hand, to their subjection to biomedical power, and on the other, to their empowerment as they regain hope, after being presented with other technological choices and chances to fulfill their dream, with other reproductive potentialities, with another possible way to become mothers, fathers and partners. The way this technological potentiality is localized points to the reality of Greek women and men, who are to a large extent biomedicalized in the sense that they have appropriated modern biomedical thinking in many facets of their lives (Georges 2008, 2014; Chatjouli 2012, 2014a).

4.3 But beyond the aforementioned facets of the biomedicalization of this emotionally challenging and lifechanging reality, and beyond the relationships and practices that are activated linked to the dominant medical regime, the process of reproduction beyond the domestic sphere is also about the information couples receive, exchange or not exchange with each other with friends and the wider family, or even with strangers on Internet forums, and how all this mobility informs (proper) partnerhood and parenthood. It is about the emergence of important other interlocutors beyond one's partner or beyond family members, about new socialities structured upon the need to communicate reproductive difficulties, choices and risks. It is about re-negotiating partnerhood, personal/public boundaries, about re-imagining intimacies, about new forms of citizenship. It is about the role of state structures and top-down norms. The biomedical technologies mediating the couples' attempts were approached therefore mostly via their socialization.

4.4 Our data point to the finding that infertility management and ART use is primarily an issue to be dealt by the couple alone and not by the extended family. Sometimes (particular) family members are not informed even after the birth of a child (via ART) and the decisions regarding the management of infertility are taken in most cases between the couple, despite the potential support offered and provided by other family members. Such findings highlight the making of a more autonomous reproductive dyad, whose gaze seems to shift away from proper parenthood and partnerhood as only imagined by long-lasting cultural norms and expectations, and move 
towards proper decision making as technology users and consumers. Within this shift women and men as partners highlight the need to protect their relationship and challenged reproductive intimacy, while at the same time women are seen to be more active as they are the ones to embody the technological challenge but also as the ones typically involved with ta tou oikou.

Choosing and relating to the biomedical expert and his team, revealed amongst many things the gaps created in the intimate project of reproduction due to infertility and the technologization of reproduction, and the need to fill these gaps by personalizing the relationship with the expert; it also brought forth the protagonistic role of the woman in the whole process of choosing and handling the expert. During the often long and exhausting period of biomedical diagnosis and treatment, both women and men reproduce the belief that because women suffer the most, they are the ones to 'say the last word' if they want to. They are the strong ones and yet the more vulnerable ones. As in the non-infertility reality of family making, women are the protagonists in making this whole thing happen. The men's narratives reveal their close involvement in the whole process of diagnosing and treating involuntary childlessness and infertility. Men underline their commitment to this common project by offering support after having first emphatically acknowledged the hardships their partner has to go through.

For instance, thirty-eight-year-old, Giannis Kastrinakis, decided to support his wife's decision to visit different clinics and doctors, go through multiple diagnostic examinations and IVF cycles at the age of thirty, although he was against this option, preferring to go for an adoption.

Giannis: I... since the very beginning, I didn't like all these. I simply didn't want...But, I wanted to help Popi and to make things easier... [...]

Popi: Giannis wanted to support me, because he saw that I couldn't really cope with it... [the prospect of not having a child]. He felt that, at least him, he had to support me. To support me whatever decisions I took.

Yet, in the process of managing infertility diagnosis and ART use, the relationship is challenged and shaken and so is the dream of parenthood. Blaming oneself and the other; feeling reduced to one's problematic reproductive potentiality often linked to sexual virility, being faced with a ruined sexual life. Forty-one-year-old, Valentina Chioti, who got a child in her first IVF, described hers and her husband's encounter with infertility as a period in their common life in which they both went through a lot of suffering:

It was strenuous, soul-destroying. Really soul-destroying! Indeed, I remember myself for a year-and-a-half, myself and my husband, I remember us being... crying all the time, being so sad.

4.8 Forty-eight-year-old, Nikitas Matsakos, a man who had not succeed in having a child after a couple of IVF cycles, said that, although for both of them infertility and ART was approached as a 'non-problem', in reality it caused considerable tension in the relationship:

[...] I have the impression that from that time onwards [meaning the period that unsuccessful efforts to conceive
naturally led them to doctors] started a 'mute', let's call it a period... we tried to get rid of this period... you know...
pretending that nothing went wrong... but actually many things went wrong, .... ... Simply, this [infertility] caused
unbelievable tension in our relationship, this situation... unbelievable tension...so strange, you know, strange... [...].

4.9 Particularly in cases of women, the frustration stemming from the difficulty in having a child is straightforwardly associated with the 'failure' of fulfilling a normative ideal of motherhood and family making as expected by their partner and the wider community (Paxson 2004). To a great extent, motherhood for them means transforming their partner/husband into a father and infertility becomes an obstacle in realizing her conceptualization of family making and proper partnership in relation to the appropriated dominant cultural norm.

4.10 For most interlocutors, infertility and ART do constitute an emotionally charged experience for the couple because they find themselves in the position in which both femininity and masculinity are being questioned. Valentina Chioti indicated: 'I felt a rejection, every month, as a woman, as a wife, as as...'. Thirty-six-year-old, Mika Konitsa who after four failed cycles of sperm injections went on with an IVF, mentioned that it was her husband who felt more insecure about his sexuality and the future of their relationship. Themis, her husband, told her: 'you'd better break up with me, go and find another partner to have a child'.

4.11 These exact challenges, faced when handling male and female infertility, triggered via the alternatives infertility poses to dominant ideas around womanhood and manhood, construct in the context of involuntary childlessness, infertility and ART use, an ethics or proper partnerhood that seems to foreground proper parenthood. The difficulty to reproduce, strengthens the couple, bonds the partners and makes this project a common one if the challenges are met during a process whereby the bonding between them is actually informed 
4.12 Despite the fact that the strain caused by infertility and the pursue of ART affects couples in various ways, in almost all cases of our interlocutors, [11] even those who haven't ended up in the birth of a child or in adoption, women and men highlighted that having to face involuntary childlessness eventually brought the couple closer and reinforced the relationship. For most informants, the key to overcome this challenge has been the reassurance that within the context of the parents' longing for a child, what comes first, is actually the well-being of the couple and the well-being of each partner, particularly the emotional and physical well-being of the woman, who is believed to suffer the most through medical interventions and reproductive failures.

4.13 Protection and continuity of the couple even beyond and despite the dream to have a child, and to become parents as constituents of proper partnerhood and parenthood were also traced when we looked into patterns of disclosure. The sharing of the story is carefully thought out in order not only to protect the emotional status of the couple during the period of trying, but also to protect the well being and image of one's partner, the image of the couple and its reproductive potentiality. Both in the case of the wider family as in the case of friends and strangers disclosure either follows a rational to avoid the stigma linked to involuntary childlessness and infertility, or it takes a completely different course, whereby sharing personal information, personal stories and insight becomes a resistance towards the stigma and social pressure as well as a bottom-up voice raising awareness about the difficulties and misuses concerning ART. In the later case 'proper partnerhood' and 'proper parenthood' are informed via socialities taking place mostly amongst co-sufferers aiming at sharing insight, exchanging personal evaluation and information, creating in other words another cultural reality of family making ( $v i s$ a vis the dominant family making paradigm with defined public/private boundaries), whereby partners and prospective parents relate also to other peoples' stories of family making and whereby the children to be born as well as the couples' continuation via reproduction embody this shared and publicly discussed reality of navigating through childlessness, social stigma and biomedicalization.

4.14 Aspects of these empowering socialities which highlight shifts in the conjugal parenting and permeability of the domestic/public, and private/public boundaries, are well traced when looking at the ways infertile couples, as technology consumers in neoliberal settings, use other technologies beyond the biomedical ones in order to make informed decisions. Greek women mostly but also Greek men turn to other co-sufferers, mostly via the Internet, but also within their wider social circle, in search of formal (mostly foreign and medical) websites and in most cases informal (lay) repro-information because of the lack of sate protection and control. Such practices also point to a culture of expertise parenting, whereby parents, or parents-to-be feel the necessity to become knowledgeable experts, to choose between various parenting and reproductive pathways, as it has been demonstrated to be the case with various aspects of aspiring parenting (Apple 1987; Gillies 2009; Lee et al 2014). Infertile couples turn to other peoples' narratives and suggestions in order to conclude and proceed. It turns out that the search for "proper informed decisions", which in turn will inform parenthood and partnerhood, is gendered especially when looking for lay expertise and emotional support. Women mostly used specialized informal internet forums where other women share their personal trajectories, offer advice and emotional support. In some cases such socializing was done anonymously while in others, persons and stories became publicly shared. New friendships were made and in some cases the support offered and received was considered crucial. In many ways the couple became stronger with the support and knowledgeable experiences of others. A webbased socialization into technical expertise was mainly the focus of men's searching, but overall, this flow of information and of personal experiences was documented as central within the overall experience and contributed to the empowerment of both women and men as technology users within an ambiguous environment of neoliberal potentialities.

\section{The Couple Challenged - The Couple Intact}

5.1 The emerging ethics of 'proper partnerhood' in the context of involuntary childlessness, infertility and ART experience, point to the couple as a tangible value that needs preserving, as a bond and unity which is constitutive but also independent of the prospect and struggle of family making. However, at the same time, this value is informed by precisely this very struggle. Both partners express the desire to protect their relationship, the wellbeing of their partner and the future of the couple. The more the hardships, the more the difficulties encountered, the bigger the challenges for the couple to overcome. In a sense all this difficulty acts as a mirror and it becomes necessary to revaluate what is truly at stake, what is worth preserving or what one can let go. Infertility and ART experiences provide the content for couples to work on their relationship, to reinvent intimacies, to re-evaluate the desire for a child, for motherhood and fatherhood, to re-think the viability of love and of shared life-pathways within the context of individualistic, fragmented and highly externalized reproduction. In many instances the wellbeing of the partner -usually the woman- and the wellbeing of the relationship acquires 
new importance. The couple becomes central in the process of family making and as such the couple becomes the family.

5.2 The work of Inhorn, in her book 'Infertility and Patriarchy: The cultural politics of gender and family life in Egypt' (1995) also highlights the way infertility bonds the couple and informs the imagining of a family even without children. The belief that children are the 'glue' that binds marriages is therefore challenged. [12] The obstacles of infertility challenge their dream and desire of parenthood but also challenge the very core of the relationship. If the couple manages to overcome this challenging period their bond becomes stronger and the desire to have a child keeps its relevance and validity, but with new thresholds. Technological reproductive potentiality further adds content to this emerging ethics of (proper) partnerhood and parenthood - the one as a precondition of the other. The challenges point to the suffering, the sacrifices, the risks taken and the endurance of the couple whereby both proper partnerhood and parenthood are tested and reaffirmed in practice.

5.3 New intimacies with new relational content are being formed for many couples. This life-changing experience sets new foundations for the couples and bonds them by turning them into family even before the birth of a child. A new type of 'heterosexual intimacy' is seen to emerge, as discussed and theorized by Ken Plummer, who in order to grasp intimacy in late modernity highlights the shifting dynamics of a "growing individuation and self reflexivity, of a 'democratisation' of personhood, of the mediazation and globalization of personal life, post-identity possibilities,..." (Plummer 2001: 239). New reproductive technologies, body transforming technologies, the public discussion of different forms of sexualities, the emergence of all sorts of new 'private problems and public troubles', are all terrains of everyday life that according to Plummer point to new intimacies and debates about them (2003).

5.4 'Proper' parenthood and partnerhood, as well as emerging forms of heterosexual intimacy, are significantly informed in the Greek ethnographic example by the sharing of repro-information and personal stories of other couples that have endured infertility. This intentional flow of information between couples, beyond the domestic sphere, actually feeds into the couple's own relationship and constructs the values attached to the preservation but also opening up of this bond. It informs the making of reproductive biosocialities mobilized in the process of family making. Partners learn from others how to be supportive within their own relationship as well as towards other co-sufferers. Family making is taking place out of body and out of home. Within such emerging forms of repro-sociality couples also train themselves in "properly" appropriating the technologies at stake. They learn how to best use the technologies for their own benefit. The technologies in such a context are at once celebrated and critically appropriated giving way to a refuelled prospect of having a child via novel pathways, at the same time they reproduce dominant normalizing cultural discourses regarding the cultural value of achieving womanhood and manhood via conjugal family making.

\section{Notes}

http://www.in-fercit.gr/en/.

We have tried to differentiate among our interlocutors in terms of gender, age $(<35,36-39,40-44,>45)$, family status (marriage/ cohabitation/ no relationship) and place of residence (Athens and nearby areas, city in the mainland, islands) as well as levels of education (Lyceum or secondary education, higher education etc.), occupation (civil servants, self-employers, house persons and unemployed) and family income (low, medium, high). The topics we were interested in discussing focused on "new" kinship relations and family formation in the context of assisted reproduction technologies and were structured around sixteen thematic axes that involved: 1) demographic details (age, family status, residency), 2) concepts of the "child" and the desire to become parent, 3) partner's participation in reproduction and child raising, 4) the reaction of relatives and friends, 5) the meanings of male and female infertility, 6) the influence of the Internet and infertility forums, 7) relations with doctors, 8) attitudes towards private clinics and/or public hospitals, 9) narrations of bodily experiences, 10) attitudes in relation to genetic material and donors, 11) stances towards the legislative context, 12) attitudes and perceptions towards (national) low birthrates, 13) continuities or discontinuities between religious faith and medicalized reproductive technology, 14) the cost of assisted reproduction technologies, 15) the cost of time, age and the 'biological' clock, 16) attitudes and perceptions towards the wider medicalization of reproduction and pregnancy. 
Following Klaus-Hoyer's, Stefan's Helmreich's and Karen-Sue Taussig's (2013) proposition to use reflexively the concept of potentiality and the politics of referentiality when discussing issues linked to the anthropology of biomedicine, we aim by using the term 'reproductive potentiality' to focus not only on the moral aspects and claims surrounding (biotechnological) potentiality but also on the related productivity and uncertainty which also present themselves when dealing with something that includes a lot of possibilities, with something that still doesn't exist, with something that might or might realize in the future, with something unknown.

Already in the mid 1980s anthropologists began to be preoccupied with the social and cultural dimensions of rapid changes in reproduction and genetics. Ultrasound, pre-genetic screening and diagnosis, assisted reproduction, surrogate motherhood, and embryo research became important topics of ethnographic and theoretical research. During the 1990s new reproduction technologies was a significant area in order to research gender, kinship, science and how power and human action can be connected. Gender studies in anthropology were mainly concerned with the meanings of infertility, the effects of ART drugs on women's bodies, the medicalization of women's bodies and the use of eggs and cryopreserved embryos for medical research, the bodily and emotional consequences of amniocentesis and ultrasound, men's power to discuss such issues compared to women's silence, and the use of ART among same-sex desiring people (Martin 1987, Franklin 1993, 1995, 1997, Rapp 1987, 1988, 1990, 1991, Ginsburg and Rapp 1991, Ragoné 1994, Inhorn 1994, 1996, 2000, 2007, 2012; Inhorn and Balen 2002, Inhorn et al. 2009, Hayden 1995, Lewin 1993, 2009, Levine 2008, Bonaccorso 2009). On the other hand, kinship emerged as a central topic in relation to ART because anthropologists specialize in the study of kinship and have analytical tools in order to study the social and cultural parameters of ART but also because ART enabled anthropologists to reconsider classical topics on kinship -i.e. what makes someone a mother or a father- from another perspective (Canell 1990, Strathern 1992a, b, 1995 and 2005, Ginsburg and Rapp 1991, 1995, Ragon é 1997, Rapp 1999, Carsten 2004, Inhorn and Birenbaum-Carmeli 2009). Finally, anthropological research on ART did not limit itself in researching gender or kinship relations. It is deeply interested in the politics of reproduction, the control and distribution of scientific knowledge, the interrelation of medical technologies with broader social, political and economic systems. (Edwards et al. 2009, Franklin 1993, 1997, Franklin and Ragoné 1998, Rapp 1999, ?onrad 2005, Thompson 2005, Birenbaum-Carmeli and Inhorn 2009, Edwards and Salazar 2009).

Athanasiou discussing the normalizing effect of top-down biopolitical discourses on reproduction, contraception, sexuality, gender, marriage and the family, which is mainly formulated by the state and the church, points to 'the constitution of intimate subjectivities according to the cultural intelligibility of reproductive heterosexuality, familial generationality and national continuity' (2006: 229).

Well portrayed in the icons of Theotokos (Christ Bearer) and Panayia Vrefokratousa-All Holy Mary holding Christ as a child in her arms.

Papataxiarchis (2013: 242) commenting on Paxson's (2004) analysis of sacrificial motherhood as central to the making of women's selves indicates: 'as a life project motherhood continues to be attached to a relational notion of the self, -a notion which provides, in the form of 'maternal agape (love)' and 'sacrifice', the archetypical and paradigmatic instance of this particular logic of self fashioning-, and that the realization of relational motherhood that 'completes' the self remains diachronically conditional upon marriage and the formation of a conjugal household'.

In Greece the number of reproductive clinics and centres was 50 in 2006 according to the European IVF-monitoring (EIM) Consortium for the European Society of Human Reproduction and Embryology (ESHRE) (de Mouzon et al. 2010: 1853). More than half were located in Athens and the remaining in other major cities. 10 belong to public hospitals (6 to university hospitals) and the rest are private (Panagiotidou-Prapa \& Prapas 2006: 236-239). Only 9 reported their results to ESHRE. This very low percentage raises questions, especially when compared to the 2003 report when 22 out of 44 clinics and centres shared their statistics. The law on 'Application of Medical Assisted Reproduction Methods' voted in 2005 perhaps had an impact. Although the 2005 Law specifically prescribed that one of the first and main tasks for the National Authority for Medical Assisted Reproduction would be to give numbers and details, the list is even nowadays far from complete. Thus, we lack any official data in relation to ART in Greece. fertilization. In everyday Greek, IVF is referred to simply as eksosomatiki (2004: 218). 
depicting changing ideas about teknopiía, Athenians frequently voice a narrative of increased "consciousness" '. This happens in a context in which a shift from the ethic of service is gradually replaced by the ethic of choice: 'As an idiom of human will replacing that of God's will in women's reproductive narratives, contemporary Athenians perceive reproductive agency differently than did their mothers and grandmothers. Women should "know why" they have children, presupposing they understand "what a child means for them" personally-not just as "a woman", or even as a Greek woman' (ibid.: 39).

The research didn't include divorced women and men with an infertility past.

'Against the intense pressures of a man's natal family to replace his wife if she doesn't conceive within 6 months to a year after their marriage, childless marriages proportionately enjoy a higher degree of "conjugal connectivity" or mutual emotional satisfaction, than marriages with offspring. Inhorn argues that while patriarchy reinforces the structural importance of natal relationships to the detriment of conjugal or personal commitments, poor urban marriages, which survive the heartbreak of infertility, enjoy a surprising egalitarianism. Couples in infertile marriages forge new identities by challenging social norms with their unique conjugal practices. Inhorn argues that this emerging heterosexual intimacy is evidence of a social potential to subvert contemporary systems of segregated patriarchy' (see Kearsly A. Stewarts' 1997 review of Inhorn 1995).

\section{References}

ABATZOGLOU G, Manolopoulos S, Papaligoura Z, and Skoulika A, (2006) (Eds.)Prosegiseis tis ipovoithoumenis anaparagogis [Approaches of assisted reproduction]. Thessaloniki: University Studio Press.

APPLE R, (1987) Mothers and Medicine: A Social History of Infant Feeding 1890-1950 Madison, WI: University of Wisconsin Press.

ATHANASIOU A, (2006) 'Bloodlines: Performing the body of the "demos", reckoning the time of the "ethnos"', Journal of Modern Greek Studies, Vol. 24, p. 229-256.

ATHANASIOU A, (2014) To ethniko soma se katastasi ektaktis anagis: I dimografiki politiki tis zois kai ta oria tou politikou in Papataxiarchis E (Eds.) Politikes kathimerinotitas: Sinoro, soma kai idiotita tou politi stin Ellada [Politics of everyday life: Border, body and citizenship in Greece], p. 455-484, Athens: Alexandria.

BIRENBAUM-CARMELI D, and Inhorn M. C, (2009) (Eds.) Assisting Reproduction, Testing Genes. Global Encounters with New Biotechnologies. New York and Oxford: Berghahn.

BONACCORSO ?, (2009) Conceiving Kinship. Assisted Conception, Procreation and Family in Southern Europe. New York-Oxford: Berghahn.

CANELL F, (1990), 'Concepts of parenthood: The Warnock Report, the Gillick debate and modern myths', American Ethnologist 17(4), p. 667-686.

CARSTEN J, (2004) After kinship. Cambridge: Cambridge University Press.

CHATJOULI A, (2012) Thalassemikes zoes. Biologiki diafora, kanonikotita, biokoinonikotita. Mia anthropologiki proseggisi [Thalassaemic lives. Biological difference, normality, biosociality. An anthropological approach]. Athens: Patakis.

CHATJOULI A, (2013) 'Anaparagogi kai kanonikotita. Biopolitikes eleghou kai anaparagogikes stratigikes - I periptosi tis Thalassemias' [Reproduction and normality. Biopolitics of control and reproductive strategies. The case of Thalassaemia] in Kantsa V (Eds.) I mitrotita sto proskinio. Sighrones erevnes stin elliniki ethnografia [Motherhood in the forefront. Recent research in Greek ethnography], p. 201-232 Athens: Alexandria.

CHATJOULI A, (2014a) 'Biokoinonikotita: Mia nea politiki tis diaforas. I periptosi tis Thalassemias' [Biosociality: A new politics of difference] in Papataxiarchis E (Eds.) Politikes tis kathimerinotitas. Sinoro, soma kai Idiotita tou Politi stin Ellada [Politics of everyday life. Border, Body and Citizenship in Greece], p. 289- 
318. Athens: Alexandria.

CHATJOULI A, (2014b) 'I anadisi tou bioiatrikou somatos kai i empeiria tis bioiatrikopoiisis' [The emergence of the biomedical body and the experience of biomedicalization] in Alexias G, Tzanakis M and Chatjouli A (Eds.) Soma ipo epitirisi. Ithikes kai politikes syndiloseis tis iatrikis tehnologias kai tis iatrikis frontidas [Body under surveillance. Ethical and political connotations of medical technology and medical care], p. 143-180. Athens: Pedio.

CHATJOULI A, Daskalaki I, and Kantsa V, (2015)Out of Body, Out of Home: Assisted Reproduction, Gender and Family in Greece, Athens: Alexandria.

CHRONAKI M, (2015) 'Experiences, uses, and significations of the home as a birth territory in a town in central Greece'. International Journal of Childbirth5 (2)

DE MOUZON J et al. (2010) 'Assisted reproductive technology in Europe, 2006: Results generated from European registers by ESHRE', Human Reproduction, Vol. 25, Issue (8), p. 1851-1862.

EDWARDS J, and Salazar C, (2009) (Eds.) European Kinship in the Age of Biotechnology. New York and Oxford: Berghahn.

FOUCAULT M, (1990). The History of Sexuality, Volume I: An Introduction. Robert Hurley, trans. New York: Vintage.

FOUCAULT M, (1997) Society Must Be Defended: Lectures at the Collège de France, 1975-1976 New York, NY: St. Martin's Press.

FOUCAULT M, (1998) The History of Sexuality Vol. 1: The Will to Knowledge. London: Penguin.

FOUNTEDAKI K, (2007) Anthropopini anaparagogi kai astiki evthini[Human reproduction and medical liability]. Athens-Thessaloniki: Sakkoula.

FRANKLIN S, (1993) 'Postmodern procreation: Representing reproductive practice', Science as Culture 3(4): p. $522-561$.

FRANKLIN S, (1995) 'Postmodern procreation: a cultural account of assisted reproduction' in Ginsburg, F. D. and Rapp R. (Eds.), Conceiving the New World Order, p. 323-345. Berkley: University of California Press.

FRANKLIN S, (1996) 'Fetal ultrasound imaging and the production of authoritative knowledge in Greece', Medical Anthropology Quarterly, Vol. 15, Issue (2), p. 157-175.

FRANKLIN S, (1997) Embodied Progress: A Cultural Account of Assisted Conception.London-New York: Routledge.

FRANKLIN S, and Ragoné H, (1998) Reproducing Reproduction. Kinship, Power and Technological Innovation. Philadelphia: University of Pennsylvania Press.

GILLIES V, (2009) ' Understandings and experiences of involved fathering in the United Kingdom: exploring classed dimensions', The Annals of the American Academy of Political and Social Science, 624, p. 4960. [doi:10.1891/2156-5287.5.2.71]

GINSBURG F, Rapp, R, (1991) 'The politics of reproduction', Annual Review of Anthropology20, p. 311-43.

GINSBURG F, Rapp, R, (1995) Conceiving the New World Order. The Global Politics of Reproduction Berkley: University of California Press.

GEORGES N. (1996) 'Abortion policy and practice in Greece'. Social Science and Medicine 42(4), p. 509-516.

GEORGES N. (2008) Bodies of Knowledge. The Medicalization of Reproduction in Greece Nashville: Vanderbilt University Press.

GEORGES N. (2013) 'Mia paremvasi san oles tis alles: Diaforopoiimena noimata tis kaisarikis tomis' [An interversion as all the others: Differentiated meanings of Caesarean section] in Kantsa V (Eds.) I mitrotita sto proskinio. Sighrones erevnes stin elliniki ethnografia [Motherhood in the forefront. Recent research in Greek ethnography], p. 233-258 Athens: Alexandria. 
GEORGES N. (2014) 'Odigos stin egimosini: Simvoules eidikon gia thn syghroni ellinida mitera' [Guide to pregnancy: Expert advice to the modern Greek woman] in Papataxiarchis E (Eds.) Politikes tis kathimerinotitas. Sinoro, soma kai idiotita tou politi stin Ellada [Politics of everyday life. Border, Body and Citizenship in Greece], p. 289-318. Athens: Alexandria.

HALKIAS A, (1998) 'Give birth for Greece! Abortion and nation in letters to the editor of the mainstream Greek press'. Journal of Modern Greek Studies, Vol. 16, Issue (1), p. 111-38.

HALKIAS A, (2004) The empty cradle of democracy. Sex, abortion and nationalism in modern Greece Durham London: Duke University Press.

HAYDEN C, (1995) 'Gender, genetics, and generation: Reformulating biology in lesbian kinship', Cultural Anthropology 10(1), p. 41-63.

INHORN M. C, (1994) The Quest for Conception: Gender, infertility, and Egyptian medical traditions. Philadelphia: University of Pennsylvania Press.

INHORN M. C, (1995) Infertility and Patriarchy. ?The Cultural Politics of Gender and Family Life in Egypt. Philadelphia: University of Pennsylvania Press.

INHORN M. C, (2000) 'Missing motherhood: Infertility, technology, and poverty in Egyptian women's lives' in H. Ragon é and Winddance T (Eds.) Ideologies and Technologies of Motherhood: Race, class, sexuality, nationalism, p. 139-168. New York: Routledge.

INHORN M. C, (2007) Reproductive Disruptions. Gender, Technology, and Bipolitics in the New Millennium New York - Oxford: Berghahn.

INHORN M. C, (2012) 'Why me? Male infertility and responsibility in the Middle East'. Men and Masculinities 16(1): p. 49-70.

INHORN M. C, and van Balen F (2002) (Eds.) Infertility around the Globe. New Thinking on Childlessness, Gender, and Reproductive Technologies. California: University of California Press.

INHORN M. C, Tjmhj-Thomsen T, and Goldberg H, (2009) (Eds.)Reconceiving the Second Sex: Men. Masculinity, and Reproduction. New York and Oxford: Berghahn.

KANTSA V, (2006) 'Oikogeniakes ipotheseis. Mitrotita kai omofiles erotikes scheseis' [Family matters. Motherhood and same-sex relationships] in Papataxiarchis E (Eds.) Peripeteies tis eterotitas. I paragogi tis politismikis diaforas sti simerini Ellada [Adventures of alterity. The production of cultural difference in contemporary Greece], p. 355-381. Athens: Alexandria.

KANTSA V, (2011) "'Late", "early", "never": Time, gender and technology in assisted reproduction'. In M. Moravec, Motherhood Online, p. 200-201. Cambridge Scholars Publishing: Newcastle.

KANTSA V, (2013a) I mitrotita sto proskinio. Sighrones erevnes stin elliniki ethnografia [Motherhood in the forefront. Recent research in Greek ethnography] (Eds.). Athens: Alexandria.

KANTSA V, (2013b) 'Eisagogi. I mitrotita os anthropologiki emmoni' [Introduction. ?otherhood as anthropological persistence] in Kantsa V (Eds.) I mitrotita sto proskinio. Sighrones erevnes stin elliniki ethnografia [Motherhood in the forefront. Recent research in Greek ethnography], p. 17-34. Athens: Alexandria. [doi:10.4324/9780203414965]

KANTSA V, (2013c), 'Arga, noris, pote. Xronos kai siggeneia' [Late, early, never. Time and kinship] in Kantsa V (Eds.) I mitrotita sto proskinio. Sighrones erevnes stin elliniki ethnografia [Motherhood in the forefront. Recent research in Greek ethnography] (Eds.), p. 315-326. Athens: Alexandria.

KANTSA V, (2014a), 'Gamilies diekdikiseis: Orates politikes, atheates paradohes' [Marriage claims: Visible politics, invisible assumptions] in Papataxiarchis E (Eds.) Politikes kathimerinotitas: Sinoro, soma kai idiotita tou politi stin Ellada [Politics of everyday life: Border, body and citizenship in Greece] (Eds.), p. 501-524. Athens: Alexandria.

KANTSA V, (2014b), 'Prosferontas elpida: Technologies somatos stin iatrika ipovoithoumeni ananparagogi' [Giving hope: Body technologies in medically assisted reproduction] in Alexias G, Tzanakis M and Chatjouli A (Eds.) Soma ipo epitirisi: Ithikes kai politikes sindiloseis tis iatrikis technologias kai tis 
kinonikis frontidas [Body under surveillance: Ethical and political connotations of medical technology and social care] (Eds.), p. 181-206. Athens: Pedio.

KONRAD M, (2005) Nameless Relations. Anonymity, Melanesia and Reproductive Gift Exchange between British Ova Donors and Recipients. New York and Oxford: Berghahn. [doi:10.1177/0002716209334295]

KOTZABASSI A, (2003) Dikaioma sti mitrotita kai texniti gonimopoiisi: Ena politiko zitima[Right to Motherhood and artificial reproduction: A political issue]. Thessaloniki: Paratiritis.

KOTZABASSI A, (2015) 'Children without kinship affiliation: the infringement of the preconditions of assisted reproduction and its consequences' in Kantsa V (Eds.) Metavallomenes sheseis. Singeneia kai iatrikos ipovoithoumeni anaparagogi [Changing relations. Kinship and Medically Assisted Reproduction], p. 6978. Athens, (In)FERCIT produced by Alexandria Publ. [in Greek].

KOUNOYERI-MANOLEDAKIS E, (2005) Texniti gonimopoiisi kai oikogeneiako dikaio. I eidiki elliniki nomothesia. Nomos 3089/2002 kai 3305/2005 [Artificial insemination and Family Law. Special Greek legislation: Laws 3089/2002 and 3305/2005]. Athens: Sakkoulas.

KOUNOYERI-MANOLEDAKIS E, (2015) 'Objective and subjective possibilities of the law on assisted reproduction' Kantsa V (Eds.) Metavallomenes sheseis. Singeneia kai iatrikos ipovoithoumeni anaparagogi [Changing relations. Kinship and Medically Assisted Reproduction], p. 107-119. Athens, (In)FERCIT produced by Alexandria Publ. [in Greek].

KRIARI-CATRANIS I, (2003) 'Human assisted procreation and human rights - The Greek response to the felt necessities of the time', European Journal of Health Law10, p.271-279.

KUPER A, (2005) The Reinvention of Primitive Society. Transformations of a Myth. New York: Routledge.

LEE E et al. (2014) Parenting Culture Studies. Basingstoke and NewYork: Palgrave Macmillan.

LEFKARITES M P, (1992) 'The sociocultural implications of modernizing childbirth among Greek women on the island of Rhodes'. Medical Anthropology 13: p. 385-412.

LEWIN E, (1993) Lesbians Mothers. Accounts of Gender in American Culture.Ithaca New York: Cornell University Press.

LEWIN E, 2009, Gay Fatherhood. Narratives of Family and Citizenship in America.Chicago and London: University of Chicago Press.

LEVINE N, (2008) 'Alternative kinship, marriage and reproduction'. Annual review of Anthropology 37, p. 375-389.

LOCK M, and Kaufert P A, (1998) Pragmatic Women and Body Politics Cambridge: Cambridge University Press.

LOIZOS P and Papataxiarchis E, (1991a), Contested Identities: Gender and Kinship in Modern Greece. Princeton: Princeton University Press.

LOIZOS P and Papataxiarchis E, (1991b) 'Introduction: Gender and kinship in marriage and alternative contexts' in Loizos P and Papataxiarchis E (Eds.) Contested identities: Gender and Kinship in Modern Greece, p. 3-25. Princeton: Princeton University Press.

MARTIN E, (1987) The Woman in the Body: A Cultural Analysis of Reproduction Boston: Bea- con Press.

MILAPIDOU M, (2011), Somatiki akeraiotita kai ipovoithoumeni anaparagogi. I poiniki evthini sto plaisio tis therapevtikis agogis [Physical integrity and assisted reproduction. Criminal responsibility in the context of treatment]. Athens-Thessaloniki: Sakkoulas. [doi:10.1215/9780822386049]

NOVAS C, (2006) 'The political economy of hope: patients' organizations, science and biovalue'.BioSocieties, 1 (3): p. 289-305.

PAPADOPOULOU L, (2015) 'Is there a 'right' to reproduce through MAR techniques?' in Kantsa V, Papadopoulou L, Zanini G (Eds.) (In)Fertile Citizens. Anthropological and Legal Challenges of Assisted Reproduction Technologies, p. 39-52. Athens: (In)FERCIT produced by Alexandria Publ.?

PAPATAXIARCHIS E, (2013) 'Shaping modern times in the Greek family' in A. Dialla, N. Maroniti (eds),State, Economy, Society (19th-20th centuries), p. 216-244. Athens: Metaichmio. 
PAPATAXIARCHIS E, (2014) 'Ekremeis diafores: Sinoro, soma kai ethnopolitismiki ipokeimenikotita stin kathimerini praxi kai politiki' [Pending differences: Border, body and national/cultural subjectivity in everyday praxis and politics] in Papataxiarchis E (Eds.), Politikes kathimerinotitas: Sinoro, soma kai idiotita tou politi stin Ellada [Politics of everyday life: Border, body and citizenship in Greece], p. 17-80. Athens: Alexandria.

PAXSON H, (2002) 'Rationilizing sex: Family planning and the making of modren lovers in urban Greece'. American Ethnologist 29(2): p. 307-334.

PAXSON H, (2003) 'With or against nature? IVF, gender and reproductive agency in Athens, Greece'. Social Science \& Medicine, Vol, 56, p. 1853-1866.

PAXSON H, (2004) Making Modern Mothers: Ethics and Family Planning in Urban Greece. Berkley: University of California Press.

PAXSON H, (2006) 'Reproduction as spiritual kin work: Orthodoxy, IVF and the moral economy of motherhood in Greece'. Culture, Medicine \& Psychiatry, Vol. 30, Issue (4), p, 481-505.

PLUMMER K, (2001) 'The Square of Intimate Citizenship', Citizenship Studies, Vol. 5 (6), p. 237-255.

PLUMMER K, (2003) Intimate Citizenship: Private Decisions and Public Dialogues Culture. Seattle: University of Washington Press.

RABINOW P, (1996) 'Artificiality and enlightenment: From sociobiology to biosociality' in Rabinow P (Eds.) Essays on the Anthropology of Reason. Princeton: Princeton University Press.

RAGON\&EACUTE; H, (1994) Surrogate Motherhood: Conception in the Heart Boulder, CO: Westview Press. [doi:10.1177/1097184X12468098]

RAPP R, (1987) 'Moral pioneers: women, men and fetuses on the frontier of reproductive technology'.Women and Health 13(1-2): p. 101-116.

RAPP R, (1988) 'The power of positive diagnosis: medical and maternal discourses on amniocentesis', in K. Michaelson (Eds.) Childbirth in America, p. 103-116. Massachusetts: Bergin and Garvey.

RAPP R, (1991) 'Moral pioneers. Women, men and fetuses on a frontier of reproductive technology' in di Leonardo M (Eds.) Gender at the Crossroads of Knowledge: Feminist Anthropology in the Postmodern Era, p. 383-395. California: University of California Press.

RAPP R, (1999) Testing Women, Testing the Fetus: The Social Impact of Amniocentesis in America New York: Routledge.

ROSE N, (2007), The Politics of Life Itself. Biomedicine, Power, and Subjectivity in the Twenty-First-Century. Princeton: Princeton University Press.

STEWART K A, (1997) 'Review of Marcia Inhorn, Infertility and Patriarchy: The Cultural Politics of Gender and Family Life in Egypt.' Women's Studies International Forum, Vol. 20, Issue (1): p. 184.

STRATHERN M, (1992a) After Nature. English Kinship in the Late Twentieth Century Cambridge: Cambridge University Press.

STRATHERN M, (1992b) Reproducing the Future: Anthropology, Kinship and the New Reproductive Technologies. Manchester: Manchester University Press.

STRATHERN M, (1995) 'Displacing knowledge: Technologies and the consequences for kinship' in F. Ginsburg and R. Rapp (Eds.), Conceiving the New World Order, p. 346-363. Berkeley, Los Angeles, London: University of California Press.

STRATHERN M, (2005) Kinship, Law and the Unexpected. Relatives are Always a Surprise.Cambridge: Cambridge University Press.

TAUSSIG K.-S, Hoyer K, and Helmreich S, (2013) 'The anthropology of potentiality in biomedicine. An introduction to Supplewment 7', Current Antyhropology 54 (7), p. 3-14 
THOMSON C, (2005) Making Parents. The Ontological Choreography of Reproductive Technologies. Cambridge Massachusetts: MIT Press.

TRAKA D, (2013) 'I mitrotita os maieftiki diadiakasia' [Motherhood as maieutics process] in Kantsa V (Eds.)I mitrotita sto proskinio. Sighrones erevnes stin elliniki ethnografia [Motherhood in the forefront. Recent research in Greek ethnography], p. 327-340. Athens: Alexandria.

TROKANAS T, (2011) Anthropini anaparagogi. I idiotiki avtonomia kai ta oria tis[Human reproduction. Private autonomy and its limits]. Athens-Thessaloniki: Sakkoula. Trokanas,

VLACHOUTSIKOU C and Teazi-Antonakopoulou I, (2013) 'Exatomikefsi ton paidion stin agalia tis oikogenias: Miteres se dialogo me mia atomistiki ideologia anatrofis se mesoastiko proastio tis Athinas' [Children's individualization in the arms of family: Mothers in dialogue with an individualistic ideology about upbringing in a middle class Athenian suburb]. in Kantsa V (Eds.) I mitrotita sto proskinio. Sighrones erevnes stin elliniki ethnografia [Motherhood in the forefront. Recent research in Greek ethnography], p. 91-114. Athens: Alexandria. 